\title{
Optimizing UNU/ICTP PFF Plasma Focus for Neon Soft X-ray Operation
}

\author{
Sor Heoh Saw, Paul Choon Keat Lee, Rajdeep Singh Rawat, and Sing Lee
}

\begin{abstract}
The United Nations University/International Centre for Theoretical Physics Plasma Focus Facility (UNU/ICTP PFF), a 3.3-kJ plasma focus, was designed for operation in deuterium with a speed factor $S$ such that the axial run-down time matches the current rise time at an end axial speed of nearly $10 \mathrm{~cm} / \mu \mathrm{s}$. For operation in neon, we first consider that a focus pinch temperature between 200 and $500 \mathrm{eV}$ may be suitable for a good yield of neon soft $X$-rays, which corresponds to an end axial speed of 6-7 cm $/ \mu \mathrm{s}$. On this basis, for operation in neon, the standard UNU/ICTP PFF needs to have its anode length $z_{0}$ reduced by some $30 \%-40 \%$ to maintain the time matching. Numerical experiments using the Lee model code are carried out to determine the optimum configuration of the electrodes for the UNU/ICTP PFF capacitor system. The results show that an even more drastic shortening of anode length $z_{0}$ is required, from the original 16 to $7 \mathrm{~cm}$, at the same time, increasing the anode radius " $a$ " from 0.95 to $1.2 \mathrm{~cm}$, to obtain an optimum yield of $Y_{\mathrm{sxr}}=9.5 \mathrm{~J}$. This represents a two- to threefold increase in the $Y_{\mathrm{sxr}}$ from that computed for the standard UNU/ICTP PFF.
\end{abstract}

Index Terms-Dense plasma focus, neon plasma, numerical experiments, soft X-ray (SXR) source.

\section{INTRODUCTION}

$\mathbf{T}$ HE UNITED Nations University/International Centre for Theoretical Physics Plasma Focus Facility (UNU/ICTP PFF) has a unique standing in the study of plasma focus. This plasma focus system was developed under the funding and support of UNU, ICTP, and the Asian African Association for Plasma Training to initiate and promote practical knowledge and skills in plasma physics, including fusion, in developing countries [1]. It is the only plasma focus machine operating in nine research laboratories in seven countries. Research studies carried out using the UNU/ICTP PFFs have led, at last count, 11 years ago [2], to the publication of more than 200 research papers, $20 \mathrm{Ph} . \mathrm{D}$. degrees, and 40 master's degrees. It has been successful in achieving its objectives and remains one of the most cost-effective and reliable plasma focus machines for the studies of dense multiradiation plasma sources.

Manuscript received March 4, 2009; revised April 17, 2009. First published June 12, 2009; current version published July 9, 2009.

S. H. Saw is with the Institute for Plasma Focus Studies, Melbourne, Vic. 3148, Australia, and also with the Centre for Plasma Research, INTI University College, Nilai 71800, Malaysia (e-mail: saw_sorheoh@intimal.edu.my).

P. C. K. Lee and R. S. Rawat are with the Radiation Sources Laboratory, Natural Sciences and Science Education, National Institute of Education, Nanyang Technological University, Singapore 637616 (e-mail: paul.lee@nie.edu.sq; Rajdeep.rawat@nie.edu.sq).

S. Lee is with the Institute for Plasma Focus Studies, Melbourne, Vic. 3148, Australia, with INTI University College, Nilai 71800, Malaysia, and with the Natural Sciences and Science Education, National Institute of Education, Nanyang Technological University, Singapore 637616 (e-mail: leesing@ optusnet.com.au).

Digital Object Identifier 10.1109/TPS.2009.2022167
The UNU/ICTP PFF is a 3.3-kJ Mather-type plasma focus system powered by a single $15-\mathrm{kV} 30-\mu \mathrm{F}$ Maxwell capacitor switched on by a simple parallel-plate swinging cascade air gap [3]. The system produces remarkably consistent focusing actions and neutron yields of $0.5-1.0 \times 10^{8}$ neutrons per discharge at 3.0 torr of deuterium operating at $15 \mathrm{kV}$ and $180 \mathrm{kA}$ [3], [4]. This was not unexpected as the UNU/ICTP PFF was designed for optimum neutron yield in deuterium. It has a speed factor $S=(I / a) / P_{0}^{0.5}$ of $97 \mathrm{kA} / \mathrm{cm}$ per [torr of deuterium] $]^{1 / 2}$ that is consistent with the range of other neutron-optimized plasma focus devices operating in deuterium [5]. The speed factor determines the speed in both the axial and radial phases. For operation in deuterium, this corresponds to just under $10 \mathrm{~cm} / \mu \mathrm{s}$ for the end axial phase (just before the start of the radial phase) and a radial speed of $25 \mathrm{~cm} / \mu$ s when the imploding shock nears the axis. The ratio of average to end axial speed for a typical focus device is around 0.6. Thus, the UNU/ICTP PFF is designed for an average axial speed of $6 \mathrm{~cm} / \mu$ s running over an anode length of $16 \mathrm{~cm}$. This ensures that the axial run-down time matches the effective current rise time of $2.6 \mu \mathrm{s}$ at an end axial speed of nearly $10 \mathrm{~cm} / \mu \mathrm{s}$ [3].

However, for operation in neon, Liu [6] and Bing [7] have shown that a focus pinch compression temperature of 200 $500 \mathrm{eV}$ is suitable for a good yield of neon soft X-rays (SXRs). For the UNU/ICTP PFF, Liu has shown that the required end axial speed is around $6-7 \mathrm{~cm} / \mu \mathrm{s}$, giving an average axial speed of around $4 \mathrm{~cm} / \mu \mathrm{s}$. In terms of time matching, this means that, for operation in neon, the standard UNU/ICTP PFF has too long an anode and that this anode has to be reduced by some $30 \%-40 \%$ to maintain the time matching. These factors in design consideration are basic and have been discussed in more detail in an introductory document (paragraph titled "Designing a new plasma focus") of the Lee model code [8]. We use these considerations as a starting point in our optimization of the UNU/ICTP PFF for neon operation. The numerical experiments, as will be seen, then go on to show that the required reduction on anode length $z_{0}$ is more drastic than expected.

\section{LeE Model Code INCORPorating Line RAdiATION}

The Lee model code couples the electrical circuit with plasma focus dynamics, thermodynamics, and radiation, enabling a realistic simulation of all gross focus properties. The basic model, described in 1984 [9], was successfully used to assist several projects [3], [10], [11]. Radiation-coupled dynamics was included in the five-phase code, leading to numerical experiments on radiation cooling [12]. The vital role of a finite small disturbance speed discussed by Potter in a $Z$-pinch situation 
[13] was incorporated together with real gas thermodynamics and radiation-yield terms. Before this "communication delay effect" was incorporated, the model consistently overestimated the radial speeds. This is serious from the point of view of neutron yields. A factor of two in shock speeds gives a factor of four in temperatures, leading to a difference in fusion cross sections of approximately 1000 at the range of temperatures that we are dealing with. This version of the code assisted other research projects [5]-[7], [14]-[16] and was web published in 2000 [17] and 2005 [18]. Plasma self-absorption was included in 2007 [16], improving the SXR yield simulation. The code has been used extensively in several machines including UNU/ICTP PFF [2]-[6], [14], [15], [19], NX2 [7], [16], [20], and NX1 [20], [21] and has been adapted for the Filippov-type plasma focus DENA [22]. A recent development is the inclusion of the neutron yield $Y_{n}$ using a beam-target mechanism [23]-[27], incorporated in recent versions [8] of the code (versions later than RADPFV5.13), resulting in realistic $Y_{n}$ scaling with $I_{\text {pinch }}$ [23], [24]. The versatility and utility of the model are demonstrated in its clear distinction of $I_{\text {pinch }}$ from $I_{\text {peak }}$ [28] and the recent uncovering of a plasma focus pinch current limitation effect [25], [26]. The description, theory, code, and a broad range of results of this "Universal Plasma Focus Laboratory Facility" are available for download from [8].

A brief description of the code is given in the following. The five phases are summarized as follows.

1) Axial phase: Described by a snowplow model with an equation of motion coupled to a circuit equation. The equation of motion incorporates the axial phase model parameters: mass and current factors $f_{m}$ and $f_{c}$, respectively. The mass swept-up factor $f_{m}$ accounts for not only the porosity of the current sheet but also for the inclination of the moving current sheet-shock front structure and all other unspecified effects which have effects equivalent to increasing or reducing the amount of mass in the moving structure-during the axial phase. The current factor $f_{c}$ accounts for the fraction of current effectively flowing in the moving structure (due to all effects such as current shedding at or near the back-wall and currentsheet inclination). This defines the fraction of current effectively driving the structure during the axial phase.

2) Radial inward shock phase: Described by four coupled equations using an elongating slug model. The first equation computes the radial inward shock speed from the driving magnetic pressure. The second equation computes the axial elongation speed of the column. The third equation computes the speed of the current sheath, also called the magnetic piston, allowing the current sheath to separate from the shock front by applying an adiabatic approximation. The fourth is the circuit equation. Thermodynamic effects due to ionization and excitation are incorporated into these equations, these effects being important for gases other than hydrogen and deuterium. Temperature and number densities are computed during this phase. A communication delay between shock front and current sheath due to the finite small disturbance speed is crucially implemented in this phase. The model parameters, radial phase mass swept-up and current factors $f_{\mathrm{mr}}$ and $f_{\mathrm{cr}}$ are incorporated in all three radial phases. The mass swept-up factor $f_{\mathrm{mr}}$ accounts for all mechanisms which have effects equivalent to increasing or reducing the amount of mass in the moving slug during the radial phase. The current factor $f_{\text {cr }}$ accounts for the fraction of current effectively flowing in the moving piston forming the back of the slug (due to all effects). This defines the fraction of current effectively driving the radial slug.

3) Radial reflected shock (RS) phase: When the shock front hits the axis, because the plasma focus is collisional, an RS develops, which moves radially outward, while the radial current-sheath piston continues to move inward. Four coupled equations are also used to describe this phase, these being for the RS moving radially outward, the piston moving radially inward, the elongation of the annular column, and the circuit. The same model parameters $f_{\mathrm{mr}}$ and $f_{\mathrm{cr}}$ are used as in the previous radial phase. The plasma temperature behind the RS undergoes a jump by a factor of approximately two.

4) Slow compression (quiescent) or pinch phase: When the outgoing RS hits the incoming piston, the compression enters a radiative phase in which, for gases such as neon, radiation emission may actually enhance the compression, where we have included energy loss/gain terms from Joule heating and radiation losses into the piston equation of motion. Three coupled equations describe this phase, these being the piston radial motion equation, the pinch column elongation equation, and the circuit equation, incorporating the same model parameters as in the previous two phases. Thermodynamic effects are incorporated into this phase. The duration of this slow compression phase is set as the time of transit of small disturbances across the pinched plasma column. The computation of this phase is terminated at the end of this duration.

5) Expanded column phase: To simulate the current trace beyond this point, we allow the column to suddenly attain the radius of the anode and use the expanded column inductance for further integration. In this final phase, the snowplow model is used, and two coupled equations are used, similar to the axial phase aforementioned. This phase is not considered important as it occurs after the focus pinch.

We note that the transition from Phase 4 to 5 is observed in laboratory measurements to occur in an extremely short time with plasma/current disruptions, resulting in localized regions of high densities and temperatures. These localized regions are not modeled in the code, which consequently computes only average uniform density and temperature, which are considerably lower than the measured peak density and temperature. However, because the four model parameters are obtained by fitting the computed to the measured total current waveform, the model incorporates the energy and mass balances equivalent, at least in the gross sense, to all the processes which are not even specifically modeled. Hence, the computed gross features such as speeds and trajectories and integrated SXR yields have been 
TABLE I

COMPUTED $Y_{\text {sxr }}\left(Q_{\text {line }}\right)$ Versus $P_{0}$ FOR STANDARd UNU/ICTP PFF With $L_{0}=110 \mathrm{nH}, C_{0}=30 \mu \mathrm{F}, R E S F=0.2, b=3.2 \mathrm{~cm}, a=0.95 \mathrm{~cm}$, AND $z_{0}=16 \mathrm{~cm}$ OPERATING AT $14 \mathrm{kV}$ With FITTED MODEL PARAMETERS $f_{m}=0.05, f_{c}=0.7, f_{\mathrm{mr}}=0.2$, AND $f_{\mathrm{cr}}=0.8$. PEAK AXIAL, Radial Shock, and Radial Piston Speeds $v_{a}, v_{s}$, AND $v_{p}$ ARE Also Tabulated. Measured Data ARe From the Ph.D. Thesis of LiU [6] Published in [20, Fig. 6(c)]

\begin{tabular}{|c|c|c|c|c|c|c|c|c|c|c|}
\hline \multicolumn{8}{|c|}{ Computed $Y_{s x r}$ vs $P_{0}$} & \multicolumn{3}{|c|}{ Measured data (Liu[6]) } \\
\hline $\begin{array}{l}P_{0} \\
\text { (Torr) }\end{array}$ & $\begin{array}{l}I_{\text {peak }} \\
(\mathrm{kA})\end{array}$ & $\begin{array}{l}I_{\text {pinch }} \\
(\mathrm{kA})\end{array}$ & $\begin{array}{l}\text { Peak } v_{a} \\
(\mathrm{~cm} / \mu \mathrm{s})\end{array}$ & $\begin{array}{l}\text { Peak } v_{s} \\
(\mathrm{~cm} / \mu \mathrm{s})\end{array}$ & $\begin{array}{l}\text { Peak } v_{p} \\
(\mathrm{~cm} / \mu \mathrm{s})\end{array}$ & $\begin{array}{c}S \\
\left(\mathrm{kA} / \mathrm{cm}[\text { Torr } \mathrm{Ne}]^{0.5}\right)\end{array}$ & $\begin{array}{c}Q_{\text {line }} \\
(\mathrm{J})\end{array}$ & $\begin{array}{c}P_{0} \\
\text { (Torr) }\end{array}$ & $\begin{array}{l}Q_{\text {line }} \\
(\mathrm{J})\end{array}$ & $\begin{array}{c}\text { error range } \\
\pm\end{array}$ \\
\hline 4.2 & 182 & 90 & 4.7 & 16.0 & 12.3 & 94 & 0.00 & 5.6 & 0.1 & 0.1 \\
\hline 4.0 & 182 & 94 & 4.8 & 17.2 & 12.9 & 96 & 0.10 & 4.5 & 1.9 & 0.3 \\
\hline 3.7 & 181 & 99 & 5.0 & 18.8 & 13.8 & 99 & 1.61 & 3.8 & 4.1 & 0.4 \\
\hline 3.5 & 181 & 103 & 5.2 & 20.2 & 14.3 & 102 & 3.19 & 3.5 & 4.1 & 0.7 \\
\hline 3.3 & 180 & 103 & 5.4 & 21.4 & 14.7 & 105 & 3.92 & 3.0 & 5.4 & 1.0 \\
\hline 3.2 & 180 & 108 & 5.5 & 22.3 & 14.9 & 106 & 3.66 & 2.7 & 3.7 & 0.4 \\
\hline 3.1 & 180 & 110 & 5.6 & 23.0 & 15.1 & 108 & 3.19 & 2.6 & 4.1 & 0.8 \\
\hline 2.5 & 178 & 119 & 6.3 & 25.2 & 16.4 & 119 & 1.36 & 2.2 & 0.9 & 0.3 \\
\hline 2.0 & 176 & 125 & 7.0 & 26.7 & 17.7 & 131 & 0.62 & 1.6 & 0.4 & 0.1 \\
\hline 1.5 & 173 & 129 & 8.0 & 29.6 & 20.5 & 149 & 0.24 & & & \\
\hline 1.0 & 169 & 130 & 9.4 & 34.6 & 24.9 & 178 & 0.07 & & & \\
\hline
\end{tabular}

extensively tested in numerical experiments for several machines and are found to be comparable with measured values.

In the code [8], neon line radiation $Q_{L}$ is calculated as follows:

$$
\frac{d Q_{L}}{d t}=-4.6 \times 10^{-31} n_{i}^{2} Z Z_{n}^{4}\left(\pi r_{p}^{2}\right) z_{f} / T
$$

where, for the temperatures of interest in our experiments, we take the SXR yield $Y_{\mathrm{sxr}}=Q_{L} . Z_{n}$ is the atomic number.

Since, in our code, $Q_{L}$ is obtained by integrating over the pinch duration, the SXR energy generated within the plasma pinch depends on the following properties: number density $n_{i}$, effective charge number $Z$, pinch radius $r_{p}$, pinch length $z_{f}$ and temperature $T$, and pinch duration.

This generated energy is then reduced by the plasma selfabsorption which depends primarily on density and temperature; the reduced quantity of energy is then emitted as the SXR yield. These effects are included in the modeling by computing volumetric plasma self-absorption factor " $A$ " derived from the photonic excitation number $M$ which is a function of $Z_{n}, n_{i}$, $Z$, and $T$. However, in our range of operation, the numerical experiments show that the self-absorption is not significant. It was first pointed out by Liu [6] that a temperature around $300 \mathrm{eV}$ is optimum for SXR production. Bing's subsequent work [7] and our experience through numerical experiments suggest that around $2 \times 10^{6} \mathrm{~K}$ (below $200 \mathrm{eV}$ ) or even a little lower could be better. Hence, unlike the case of neutron scaling, for SXR scaling, there is an optimum small range of temperatures ( $T$ windows) to operate.

\section{NUMERICAL EXPERIMENTS ON STANDARD UNU/ICTP PFF}

To start the numerical experiments, we select a discharge current trace of the UNU/ICTP PFF taken with a Rogowski coil. The following bank, tube, and operation parameters (near the peak SXR yield) are used:

1) bank: static inductance $L_{0}=110 \mathrm{nH}, C_{0}=30 \mu \mathrm{F}$, and stray resistance $r_{0}=12 \mathrm{~m} \Omega$;

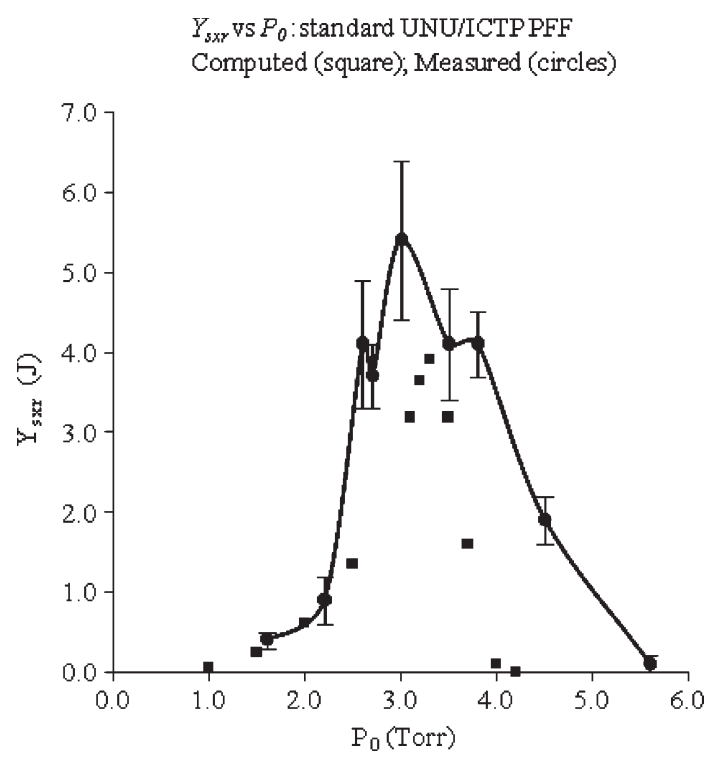

Fig. 1. Computed $Y_{\mathrm{sxr}}$ versus $P_{0}$ compared to measured [6] $Y_{\mathrm{sxr}}$ versus $P_{0}$ for standard UNU/ICTP PFF with $L_{0}=110 \mathrm{nH}, C_{0}=30 \mu \mathrm{F}, R E S F=0.2$, $b=3.2 \mathrm{~cm}, a=0.95 \mathrm{~cm}$, and $z_{0}=16 \mathrm{~cm}$ operated at $14 \mathrm{kV}$ in neon, with fitted model parameters $f_{m}=0.05, f_{c}=0.7, f_{\mathrm{mr}}=0.2$, and $f_{\mathrm{cr}}=0.8$.

2) tube: cathode radius $b=3.2 \mathrm{~cm}$, anode radius $a=$ $0.95 \mathrm{~cm}$, and anode length $z_{0}=16 \mathrm{~cm}$;

3) operation: voltage $V_{0}=14 \mathrm{kV}$ and pressure $P_{0}=3$ torr neon.

The computed total discharge current waveform is fitted to the measured values by varying model parameters $f_{m}, f_{c}, f_{\mathrm{mr}}$, and $f_{\text {cr }}$ one by one until the computed waveform agrees with the measured waveform. First, the axial model factors $f_{m}$ and $f_{c}$ are adjusted (fitted) until the computed rising slope of the total current trace and the rounding off of the peak current as well as the peak current itself are in reasonable (typically good) fit with the measured total current trace. Then, we proceed to adjust (fit) the radial phase model factors $f_{\mathrm{mr}}$ and $f_{\mathrm{cr}}$ until the computed slope and depth of the dip agree with the measured values. In this case, the following fitted model parameters are obtained: $f_{m}=0.05, f_{c}=0.7, f_{\mathrm{mr}}=0.2$, and $f_{\mathrm{cr}}=0.8$. 
TABLE II

COMPUTED $Y_{\text {Sxr }}\left(Q_{\text {line }}\right)$ VERSUS $P_{0}$ FOR OPTIMIZED UNU/ICTP PFF With $L_{0}=110 \mathrm{nH}, C_{0}=30 \mu \mathrm{F}$, AND $R E S F=0.2$, OPERATING AT $14 \mathrm{kV}$ With FITTED MODEl PARAMETERS $f_{m}=0.05, f_{c}=0.7, f_{\mathrm{mr}}=0.2$, AND $f_{\mathrm{cr}}=0.8$. OPTIMIZATION CARRIED OUT WITH FIXED $c=3.4$ BUT

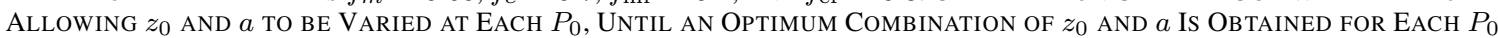

\begin{tabular}{ccccccccccc}
\hline $\begin{array}{c}b \\
(\mathrm{~cm})\end{array}$ & $\begin{array}{c}a \\
(\mathrm{~cm})\end{array}$ & $\begin{array}{c}z_{0} \\
(\mathrm{~cm})\end{array}$ & $\begin{array}{c}P_{0} \\
(\text { Torr })\end{array}$ & $\begin{array}{c}I_{\text {peak }} \\
(\mathrm{kA})\end{array}$ & $\begin{array}{c}I_{\text {pinch }} \\
(\mathrm{kA})\end{array}$ & $\begin{array}{c}\text { Peak } v_{a} \\
(\mathrm{~cm} / \mu \mathrm{s})\end{array}$ & $\begin{array}{c}\text { Peak } v_{s} \\
(\mathrm{~cm} / \mu \mathrm{s})\end{array}$ & $\begin{array}{c}\text { Peak } v_{p} \\
(\mathrm{~cm} / \mu \mathrm{s})\end{array}$ & $\begin{array}{c}S \\
\left(\mathrm{kA} / \mathrm{cm}[\mathrm{Torr} \mathrm{Ne}]^{0.5}\right)\end{array}$ & $\begin{array}{c}Q_{\text {line }} \\
(\mathrm{J})\end{array}$ \\
\hline 3.20 & 0.951 & 6.0 & 5.0 & 182 & 140 & 4.3 & 23.1 & 15.1 & 86 & 8.44 \\
\hline 3.80 & 1.129 & 7.0 & 3.5 & 183 & 140 & 4.5 & 23.3 & 15.1 & 87 & 87 \\
\hline 4.09 & 1.213 & 7.0 & 3.0 & 183 & 139 & 4.5 & 23.0 & 15.1 & 8.04 \\
\hline 4.45 & 1.322 & 7.0 & 2.5 & 183 & 138 & 4.5 & 23.2 & 15.1 & 8.01 \\
\hline 4.94 & 1.466 & 7.0 & 2.0 & 183 & 137 & 4.6 & 23.2 & 15.1 & 88 \\
\hline 5.63 & 1.673 & 6.0 & 1.5 & 181 & 136 & 4.4 & 23.1 & 15.1 & 88 & 88 \\
\hline 6.78 & 2.014 & 6.0 & 1.0 & 180 & 134 & 4.5 & 23.3 & 15.1 & 9.96 \\
\hline
\end{tabular}

These fitted values of the model parameters are then used for the computation of all the discharges at various pressures to obtain Table I.

It is evident from Table I that the peak value of the total discharge current $I_{\text {peak }}$ decreases with decreasing pressure. This is due to the increasing dynamic resistance (rate of change of plasma inductance $d L / d t$ gives rise to a dynamic resistance equal to $0.5 d L / d t$ ) due to the increasing current-sheath speed as pressure is decreased. We note that, on the contrary, the current $I_{\text {pinch }}$ that flows through the pinched plasma column increases with decreasing pressure. This is due to the shifting of the pinch time closer and closer toward the time of peak current as the current sheet moves faster and faster. Even at 1 torr, the current sheet (with a peak end axial value of $9.4 \mathrm{~cm} / \mu \mathrm{s}$ ) is still not quite fast enough for best matching and reaches the end just after the peak of the circuit current (which peaks at $2.6 \mu \mathrm{s}$, a little earlier than the unloaded rise time). For the standard UNU/ICTP PFF with an anode length of $16 \mathrm{~cm}$, the operating pressure has to be just below 0.9 torr in neon for the current sheet to reach the end of the anode at peak total current. Below 0.9 torr, the $I_{\text {pinch }}$ starts to decrease as the pinch time now occurs before current peak time. Moreover, $I_{\text {peak }}$ is also dropping because of the still increasing dynamic resistance. As the pressure is decreased, the increase in $I_{\text {pinch }}$ may be expected to favor $Y_{\mathrm{sxr}}$; however, there is a competing effect that decreasing pressure reduces the number density. The interaction of these competing effects will decide on the actual yield versus pressure behavior as shown in the computed results.

A plot of $Y_{\text {sxr }}$ versus $P_{0}$ is shown in Fig. 1. The data of measured $Y_{\mathrm{sxr}}$ with $P_{0}$ were obtained by Liu [6] using a fivechannel p-i-n SXR detector confirmed by a calorimeter. Comparing computed $Y_{\text {sxr }}$ versus $P_{0}$ data with the measured $Y_{\text {sxr }}$ versus $P_{0}$ data shows general agreement between our computed curve and the measured curve. The differences are as follows. Liu's measured optimum point is at 3.0 torr and has an optimum $Y_{\mathrm{sxr}}$ of $5.4 \pm 1 \mathrm{~J}$. This compares with our computed optimum pressure of 3.3 torr and computed optimum $Y_{\mathrm{sxr}}$ of $3.9 \mathrm{~J}$. The drop-off of $Y_{\mathrm{sxr}}$ on the low-pressure side is very similar, but our computed drop-off on the high $P_{0}$ side shows a sharper dropoff compared with Liu's data. This comparison of data from our numerical experiments with Liu's careful measurements gives us confidence that the numerical experiments provide realistic values and pressure dependence of neon $Y_{\text {sxr }}$ comparable with measured neon $Y_{\text {sxr }}$ versus $P_{0}$ data, although the computed values appear to be significantly on the low side.

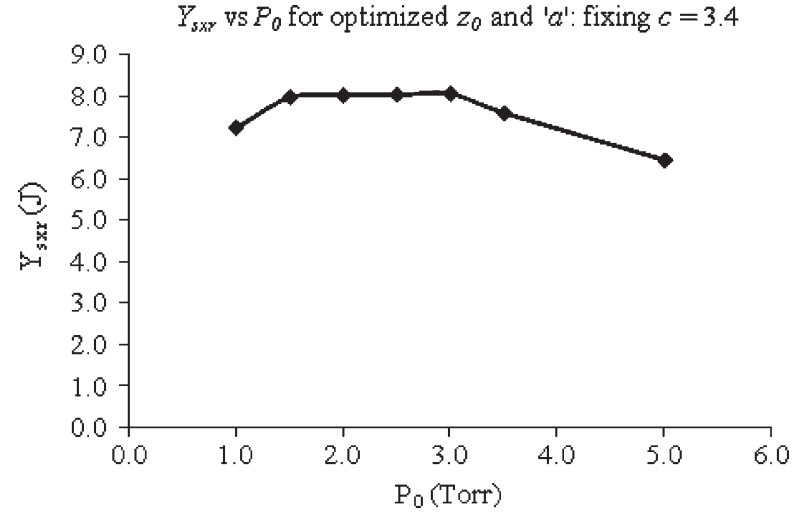

Fig. 2. Computed $Y_{\text {sxr }}\left(Q_{\text {line }}\right)$ versus $P_{0}$ for optimized UNU/ICTP PFF with $L_{0}=110 \mathrm{nH}, C_{0}=30 \mu \mathrm{F}$, and $R E S F=0.2$, operated at $14 \mathrm{kV}$ in neon, with fitted model parameters $f_{m}=0.05, f_{c}=0.7, f_{\mathrm{mr}}=0.2$, and $f_{\mathrm{cr}}=$ 0.8 . Optimization is carried out with fixed $c=3.4$ but allowing $z_{0}$ and $a$ to be varied at each $P_{0}$, until an optimum combination of $z_{0}$ and $a$ is obtained for each $P_{0}$.

\section{OPTIMIZING FOR A PRACTICAL OPTIMUM CONFIGURATION}

Next, we carry out numerical experiments to determine the optimum configuration for the electrodes using the UNU/ICTP PFF capacitor system. We retain the capacitor bank parameters of the UNU/ICTP PFF operating at $14 \mathrm{kV}$ in neon with $L_{0}=$ $110 \mathrm{nH}, C_{0}=30 \mu \mathrm{F}$, and $R E S F=0.2$. We also kept the ratio of the outer to inner electrode constant at $c=b / a=3.4$ and retained model parameters $f_{m}=0.05, f_{c}=0.7, f_{\mathrm{mr}}=$ 0.2 , and $f_{\text {cr }}=0.8$. To check that it is reasonable to retain model parameters, we ran the code for $z_{0}=18 \mathrm{~cm}$ and $a=$ $0.85 \mathrm{~cm}$ and found that the maximum SXR yield of $2.6 \mathrm{~J}$ at 3.3 torr also compares well with the measurements by Mohammadi et al. [29].

We then parametrically varied $P_{0}, z_{0}$, and " $a$ " in that parametric order and obtained Table II which gives us the optimum combination of $z_{0}$ and $a$ for each given $P_{0}$, each optimum combination being the result of a series of numerical experiments systematically varying $z_{0}$ and $a$. From Table II, for a computed optimized $Y_{\text {sxr }}$, Fig. 2 is shown.

From the numerical experiments, for $c=3.4$, the optimum $Y_{\mathrm{sxr}}$ is $8.04 \mathrm{~J}$ at $a=1.213 \mathrm{~cm}, z_{0}=7 \mathrm{~cm}$, and $P_{0}=3$ torr. This compares with a pressure-optimum yield of $Y_{\mathrm{sxr}}=3.9 \mathrm{~J}$ at 3.3 torr for the standard UNU/ICTP PFF which is operated with a fixed combination of $z_{0}=16 \mathrm{~cm}$ and $a=0.95 \mathrm{~cm}$. 
TABLE III

COMPUted $Y_{\text {Sxr }}\left(Q_{\text {line }}\right)$ Versus $P_{0}$ FOR Practical Optimized UNU/ICTP PFF With $L_{0}=110 \mathrm{nH}, C_{0}=30 \mu$ F, AND $R E S F=0.2$, OPERATING AT $14 \mathrm{kV}$ With FitTed Model Parameters $f_{m}=0.05, f_{c}=0.7, f_{\mathrm{mr}}=0.2$, AND $f_{\mathrm{cr}}=0.8$; Using Optimized Combination of $z_{0}=7 \mathrm{~cm}$ AND $a=1.2 \mathrm{~cm}$ BUt With A CATHODE RADIUS FiXed AT $b=3.2 \mathrm{~cm}$

\begin{tabular}{|c|c|c|c|c|c|c|c|}
\hline $\begin{array}{l}P_{0} \\
\text { (Torr) } \\
\end{array}$ & $\begin{array}{l}I_{\text {peak }} \\
(\mathrm{kA}) \\
\end{array}$ & $\begin{array}{l}I_{\text {pinch }} \\
(\mathrm{kA}) \\
\end{array}$ & $\begin{array}{l}\text { Peak } v_{a} \\
(\mathrm{~cm} / \mu \mathrm{s})\end{array}$ & $\begin{array}{l}\text { Peak } v_{s} \\
(\mathrm{~cm} / \mu \mathrm{s}) \\
\end{array}$ & $\begin{array}{l}\text { Peak } v_{p} \\
(\mathrm{~cm} / \mu \mathrm{s}) \\
\end{array}$ & $\begin{array}{c}S \\
\left(\mathrm{kA} / \mathrm{cm}[\text { Torr Ne}]^{0.5}\right) \\
\end{array}$ & $\begin{array}{c}Q_{\text {line }} \\
(\mathrm{J})\end{array}$ \\
\hline 6.0 & 188 & 140 & 3.9 & 16.3 & 12.4 & 64 & 0.00 \\
\hline 5.0 & 187 & 141 & 4.3 & 18.1 & 13.5 & 70 & 0.12 \\
\hline 4.0 & 186 & 141 & 4.6 & 20.4 & 14.3 & 77 & 6.41 \\
\hline 3.5 & 184 & 141 & 4.9 & 21.7 & 14.8 & 82 & 9.47 \\
\hline 3.2 & 183 & 140 & 5.0 & 22.9 & 15.0 & 85 & 8.59 \\
\hline 3.1 & 182 & 140 & 5.1 & 23.2 & 15.1 & 86 & 8.15 \\
\hline 3.0 & 182 & 139 & 5.2 & 23.5 & 15.2 & 88 & 7.31 \\
\hline 2.5 & 179 & 138 & 5.5 & 25.1 & 15.8 & 94 & 4.26 \\
\hline 2.0 & 175 & 135 & 5.9 & 25.3 & 16.4 & 103 & 2.22 \\
\hline 1.5 & 168 & 130 & 6.5 & 26.2 & 17.1 & 114 & 0.98 \\
\hline 1.0 & 158 & 123 & 7.4 & 28.1 & 19.1 & 132 & 0.33 \\
\hline
\end{tabular}

The length of the optimum anode may seem to be surprisingly short compared with our initial expectations. This is because the numerical experiments show that the optimum end axial speed (which is also the peak axial speed) for the case of $c=b / a=3.4$ is $4.5 \mathrm{~cm} / \mu \mathrm{s}$. The axial transit time then computes to be $2.54 \mu \mathrm{s}$, which, added to a radial transit time of $0.15 \mu \mathrm{s}$, means that the pinch time occurs at $2.69 \mu \mathrm{s}$, which is only $0.1 \mu \mathrm{s}$ from the loaded capacitor bank current rise time of $2.6 \mu \mathrm{s}$. The computation shows that this time matches the loaded capacitor bank discharge characteristics best in terms of energy transfer efficiency.

We next note that, practically, it is technically difficult to change the dimensions of outer radius $b$, unless the whole electrode system and input flange system of the device is completely redesigned. On the other hand, if we keep the outer electrode unchanged and use a screw-on anode, the screw-on part can be designed to be screwed onto an anode stub that keeps the original radius until it just emerges out of the insulator sleeve, at which point it is cut short and has its radius converted to that of the screw-on part. Then, the screw-on part of the anode can have the optimized radius $a$ and anode length $z_{0}$. The length of the cathode can be correspondingly shortened.

We therefore continue with the numerical experiments, keeping $b=$ constant at the original value of $3.2 \mathrm{~cm}$, changing $a$ to $1.2 \mathrm{~cm}$ with $z_{0}=7 \mathrm{~cm}$, and varying pressure to find this "practical optimum." The results are shown in Table III.

This gives us a practical optimum configuration of $b=$ $3.2 \mathrm{~cm}$ (unchanged from the original cathode radius of the standard UNU/ICTP PFF), $a=1.2 \mathrm{~cm}$, and $z_{0}=7 \mathrm{~cm}$, giving a practical optimum yield of $9.5 \mathrm{~J}$ at a $P_{0}$ of 3.5 torr. The slightly higher yield compared with that in Table II is due to the reduced ratio " $c$ " from 3.4 to 2.7. An earlier study has shown that reducing $c$, down to certain limits, has a beneficial effect in the case of neutron production operating in deuterium [24], and we have also confirmed through numerical experiments that this effect is also observed for neon $Y_{\mathrm{sxr}}$. The practical optimized results are shown in Fig. 3.

We could, of course, proceed to reduce $c$ further and continue with further parametric variations of anode radius $a$ and length $z_{0}$ to obtain small incremental improvements in SXR yields. However, for a small device, reducing $c$ further will have dif-

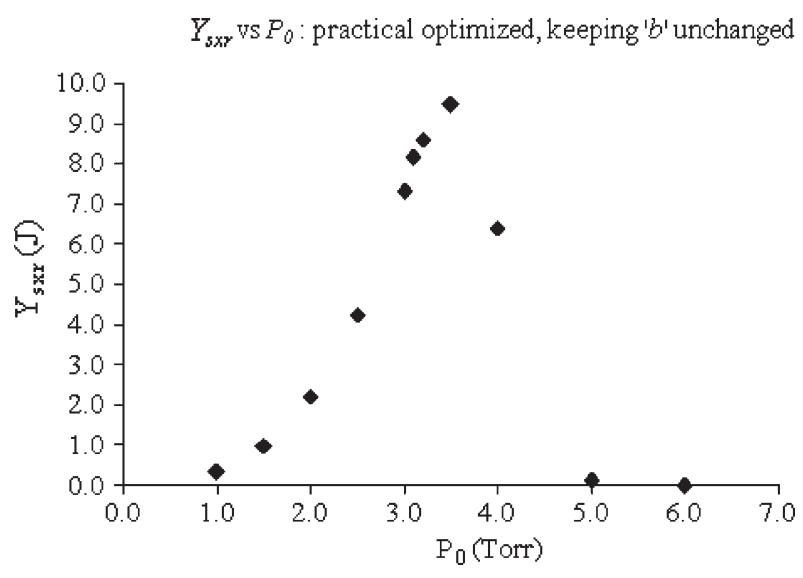

Fig. 3. Computed $Y_{\mathrm{Sxr}}\left(Q_{\text {line }}\right)$ versus $P_{0}$ for practical optimized UNU/ICTP PFF with $L_{0}=110 \mathrm{nH}, C_{0}=30 \mu \mathrm{F}$, and $R E S F=0.2$, operated at $14 \mathrm{kV}$ in neon, with fitted model parameters $f_{m}=0.05, f_{c}=0.7, f_{\mathrm{mr}}=0.2$, and $f_{\mathrm{cr}}=0.8$, using optimized combination of $z_{0}=7 \mathrm{~cm}$ and $a=1.2 \mathrm{~cm}$ but with cathode radius $b=3.2 \mathrm{~cm}$.

ficulties in terms of a very small channel width. Moreover, we are confident that the practical optimum configuration we have found will form a good basis for an easily achievable practical design to optimize the UNU/ICTP PFF for neon SXR operation. We also observed that the optimum configuration for neon SXR operation has remarkably little variation in the $S$ values, the values ranging from 82 to $87 \mathrm{kA} / \mathrm{cm}$ per [torr of neon] $]^{1 / 2}$.

\section{CONCLUSiON}

A practical optimum configuration for UNU/ICTP PFF plasma focus for neon SXR operation is rigorously determined from numerical experiments using the Lee model code. By shortening the anode length $z_{0}$ from 16 to $7 \mathrm{~cm}$ and increasing the anode radius $a$ from 0.95 to $1.2 \mathrm{~cm}$, it is predicted that an optimum yield of $Y_{\mathrm{sxr}}=9.5 \mathrm{~J}$ can be achieved. Moreover, keeping cathode design unchanged with $b$ unchanged at $3.2 \mathrm{~cm}$, it is a simple matter, technically, to use a screw-on part to increase the anode radius. It would be interesting to see if the predicted two- to threefold increase in $Y_{\mathrm{sxr}}$ going from the standard UNU/ICTP PFF anode to the optimized anode may be achieved in the laboratory. We note that an examination 
of Liu's data and the more recent data of Rawat et al. [30] seems to indicate the possibility that our numerical experiments may be systematically underestimating the $Y_{\mathrm{sxr}}$ of the standard UNU/ICTP PFF. It is important then that, when laboratory experiments are carried out, the measured $Y_{\mathrm{sxr}}$ from the practical optimized UNU/ICTP PFF should be compared with that from the standard device, simply by switching anodes and relevant pressures, everything else being kept constant.

\section{REFERENCES}

[1] S. Lee and C. S. Wong, "Initiating and strengthening plasma research in developing countries," Phys. Today, vol. 59, no. 5, pp. 3136, May 2006. ICTP Open Access Archive. [Online]. Available: http://eprints.ictp.it/273/

[2] S. Lee, in Twelve Years of UNU/ICTP PFF-A Review. Trieste, Italy: Abdus Salam ICTP, 1998, pp. 5-34. IC/ 98/ 231, ICTP Open Access Archive. [Online]. Available: http://eprints.ictp.it/31/

[3] S. Lee, T. Y. Tou, S. P. Moo, M. A. Eissa, A. V. Gholap, K. H. Kwek, S. Mulyodrono, A. J. Smith, S. Suryadi, W. Usada, and M. Zakaullah, "A simple facility for the teaching of plasma dynamics and plasma nuclear fusion," Amer. J. Phys., vol. 56, no. 1, pp. 62-68, Jan. 1988.

[4] S. V. Springham, S. Lee, and M. S. Rafique, "Correlated deuteron energy spectra and neutron yield for a $3 \mathrm{~kJ}$ plasma focus," Plasma Phys. Control. Fusion, vol. 42, no. 10, pp. 1023-1032, Oct. 2000.

[5] S. Lee and A. Serban, "Dimensions and lifetime of the plasma focus pinch," IEEE Trans. Plasma Sci., vol. 24, no. 3, pp. 1101-1105, Jun. 1996.

[6] M. Liu, "Soft X-rays from compact plasma focus," Ph.D. dissertation, NIE, Nanyang Technological Univ., Singapore, 2006. ICTP Open Access Archive. [Online]. Available: http://eprints.ictp.it/327/

[7] S. Bing, "Plasma dynamics and X-ray emission of the plasma focus," Ph.D. dissertation, NIE, Nanyang Technological Univ., Singapore, 2000. ICTP Open Access Archive. [Online]. Available: http://eprints.ictp.it/99/

[8] S. Lee, Radiative Dense Plasma Focus Computation Package: RADPF. [Online]. Available: http://www.intimal.edu.my/school/fas/UFLF/ File1RADPF.htm, http://www.plasmafocus.net/IPFS/modelpackage/File1 RADPF.htm

[9] S. Lee, "Plasma focus model yielding trajectory and structure," in Radiations in Plasmas, vol. II, B. McNamara, Ed. Singapore: World Scientific, 1984, pp. 978-987.

[10] T. Y. Tou, S. Lee, and K. H. Kwek, "Non perturbing plasma focus measurements in the run-down phase," IEEE Trans. Plasma Sci., vol. 17, no. 2, pp. 311-315, Apr. 1989.

[11] S. Lee, "A sequential plasma focus," IEEE Trans. Plasma Sci., vol. 19, no. 5, pp. 912-919, Oct. 1991.

[12] J. bin Ali, "Development and studies of a small plasma focus," Ph.D. dissertation, Universiti Teknologi Malaysia, Malaysia, 1990.

[13] D. E. Potter, "The formation of high-density z-pinches," Nucl. Fus., vol. 18, pp. 813-823, 1978.

[14] A. Serban and S. Lee, "Experiments on speed-enhanced neutron yield from a small plasma focus," J. Plasma Phys., vol. 60, no. 1, pt. 1, pp. 3-15, Aug. 1998.

[15] M. H. Liu, X. P. Feng, S. V. Springham, and S. Lee, "Soft X-ray measurement in a small plasma focus operated in neon," IEEE Trans. Plasma Sci., vol. 26, no. 2, pp. 135-140, Apr. 1998.

[16] D. Wong, P. Lee, T. Zhang, A. Patran, T. L. Tan, R. S. Rawat, and S. Lee, "An improved radiative plasma focus model calibrated for neonfilled NX2 using a tapered anode," Plasma Sources Sci. Technol., vol. 16, no. 1, pp. 116-123, Feb. 2007.

[17] S. Lee, 2000-2007. [Online]. Available: http://ckplee.myplace.nie.edu.sg/ plasmaphysics/

[18] S. Lee, ICTP Open Access Archive, 2005. [Online]. Available: http://eprints.ictp.it/85/

[19] M. A. Mohammadi, S. Sobhanian, C. S. Wong, S. Lee, P. Lee, and R. S. Rawat, "The effect of anode shape on neon soft X-ray emissions and current sheath configuration in plasma focus device," J. Phys. D, Appl. Phys., vol. 42, no. 4, Feb. 2009. 045203 (10pp).

[20] S. Lee, P. Lee, G. Zhang, X. Feng, V. A. Gribkov, M. Liu, A. Serban, and T. Wong, "High rep rate high performance plasma focus as a powerful radiation source," IEEE Trans. Plasma Sci., vol. 26, no. 4, pp. 1119-1126, Aug. 1998.

[21] E. P. Bogolyubov, V. D. Bochkov, V. A. Veretennikov, L. T. Vekhoreva, V. A. Gribkov, A. V. Dubrovskii, Y. P. Ivanov, A. I. Isakov, O. N. Krokhin, P. Lee, S. Lee, V. Y. Nikulin, A. Serban, P. V. Silin, X. Feng, and
G. X. Zhang, "A powerful soft X-ray source for X-ray lithography based on plasma focusing," Phys. Scr., vol. 57, no. 4, pp. 488-494, 1998.

[22] V. Siahpoush, M. A. Tafreshi, S. Sobhanian, and S. Khorram, "Adaptation of Sing Lee's model to the Filippov type plasma focus geometry," Plasma Phys. Control. Fusion, vol. 47, no. 7, pp. 1065-1075, Jul. 2005.

[23] S. Lee and S. H. Saw, "Neutron scaling laws from numerical experiments," J. Fusion Energy, vol. 27, no. 4, pp. 292-295, Dec. 2008.

[24] S. Lee, "Current and neutron scaling for megajoule plasma focus machines," Plasma Phys. Control. Fusion, vol. 50, no. 10, p. 105005 (14pp), Oct. 2008.

[25] S. Lee and S. H. Saw, "Pinch current limitation effect in plasma focus," Appl. Phys. Lett., vol. 92, no. 2, p. 021 503, Jan. 2008.

[26] S. Lee, P. Lee, S. H. Saw, and R. S. Rawat, "Numerical experiments on plasma focus pinch current limitation," Plasma Phys. Control. Fusion, vol. 50, no. 6, Jun. 2008. 065012 (8pp).

[27] V. A. Gribkov, A. Banaszak, B. Bienkowska, A. V. Dubrovsky, I. Ivanova-Stanik, L. Jakubowski, L. Karpinski, R. A. Miklaszewski, M. Paduch, M. J. Sadowski, M. Scholz, A. Szydlowski, and K. Tomaszewski, "Plasma dynamics in the PF-1000 device under fullscale energy storage: II. Fast electron and ion characteristics versus neutron emission parameters and gun optimization perspectives," J. Phys. D, Appl. Phys., vol. 40, no. 12, pp. 3592-3607, Jun. 2007.

[28] S. Lee, S. H. Saw, P. C. K. Lee, R. S. Rawat, and H. Schmidt, "Computing plasma focus pinch current from total current measurement," Appl. Phys. Lett., vol. 92, no. 11, p. 111 501, Mar. 2008.

[29] M. A. Mohammadi, R. Verma, S. Sobhanian, C. S. Wong, S. Lee, S. V. Springham, T. L. Tan, P. Lee, and R. S. Rawat, "Neon soft X-ray emission studies from the UNU-ICTP plasma focus operated with longer than optimal anode length," Plasma Sources Sci. Technol., vol. 16, no. 4, pp. 785-790, Nov. 2007

[30] R. S. Rawat, T. Zhang, C. B. L. Phua, J. X. Y. Then, K. A. Chandra, X. Lin, A. Patran, and P. Lee, "Effect of insulator sleeve length on soft X-ray emission from a neon-filled plasma focus device," Plasma Sources Sci. Technol., vol. 13, no. 4, pp. 569-575, Nov. 2004.

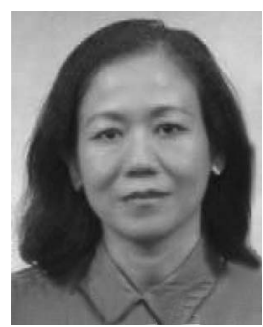

Sor Heoh Saw received the B.Sc. (with honors) and $\mathrm{Ph} . \mathrm{D}$. degrees in physics from the University of Malaya, Kuala Lumpur, Malaysia, in 1985 and 1991 , respectively, and the M.A. degree in educational management from the University of Nottingham, Nottingham, U.K., in 1997.

She is an Associate Professor and the VicePresident for Teaching and Learning with the INTI University College, Nilai, Malaysia, where she currently heads the Centre for Plasma Research. She is also an Associate with the Institute of Plasma Focus Studies, Melbourne, Australia, and the designated delegate of the INTI University College for Asian African Association for Plasma Training. Her current research interests include plasma physics and improving teaching.

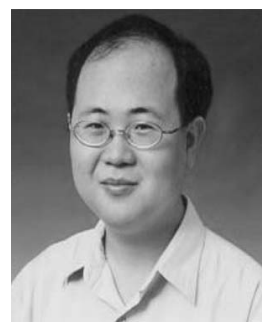

Paul Choon Keat Lee received the B.Sc. (with honors) and Ph.D. degrees from the Imperial College, London, U.K., in 1992 and 1996, respectively, and the PGDipTHE from Nanyang Technological University, Singapore, in 1999.

$\mathrm{He}$ is currently an Associate Professor with the Radiation Sources Laboratory, Natural Sciences and Science Education, National Institute of Education, Nanyang Technological University. He was a Visiting Associate Professor at the University of Washington, Seattle, and at the Technological Educational Institute, Crete, in 2007. His current research interests include plasma physics, materials science, and physics education. 


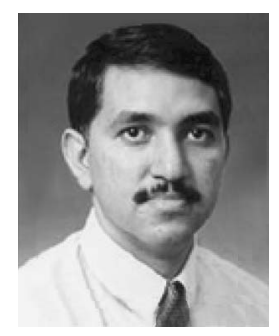

Rajdeep Singh Rawat received the B.Sc. (with honors), M.Sc., and Ph.D. degrees from the University of Delhi, Delhi, India, in 1985, 1987, and 1994, respectively.

$\mathrm{He}$ is currently an Associate Professor with the Radiation Sources Laboratory, Natural Sciences and Science Education, National Institute of Education, Nanyang Technological University, Singapore. He has authored 79 research papers in journals of international repute and about 45 research papers in conference proceedings. His current research interests include the development of repetitive miniature plasma focus devices as portable neutron source, charged particle and radiation emission from focus devices for nanophase material synthesis, ion-implantations and lithography applications, magnetic nanoparticles/nanocomposites, and diluted magnetic semiconductor thin films of transition-metal-doped $\mathrm{ZnO}$ using pulsed laser depositions.

Dr. Rawat is currently the Honorary Secretary of the Asian African Association for Plasma Training and a Council Member of the Institute of Physics, Singapore.

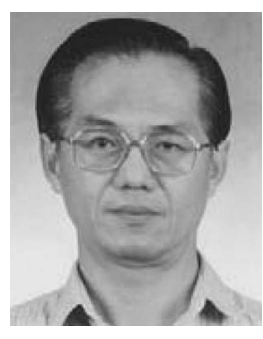

Sing Lee received the B.Sc. and M.Sc. degrees from the University of Malaya (UM), Kuala Lumpur, Malaysia, in 1964 and 1966, respectively, and the $\mathrm{Ph} . \mathrm{D}$. degree from the Australian National University, Canberra, Australia, in 1970

He was an Alexander von Humboldt Fellow (1975-1976) with Kernforschunglange, Juelich, West Germany, a Commonwealth Academic Staff Fellow (1981-1982) with the Imperial College, London, U.K., and a Visiting Professor and a United Nations University Special Fellow (1986-1987) at Flinders University, South Australia. He was a Professor of Applied Physics with UM, where he headed research groups in plasma and pulse technology and the Physics Department. He was the Head of the Division of Physics and the Head of the Academic Group of Natural Sciences, National Institute of Education, Nanyang Technological University (NTU/NIE), Singapore. He is currently the Founder Principal of the (web-based) Institute for Plasma Focus Studies, Melbourne, Australia, and an Adjunct Professor (honorary) with the Natural Sciences and Science Education, NTU/NIE, and with INTI University College, Nilai, Malaysia.

Dr. Lee was the Founder President of the Asian African Association for Plasma Training (AAAPT), the Associate Director of the AAAPT Research and Training Centre, Institute of Physics, Academia Sinica, Beijing, the Far Eastern Representative of the International Centre for Theoretical Physics, and an ardent advocate and implementor of south-south technology creation and transfer, particularly in plasma fusion, laser, and pulse technology. He is also a Chartered Physicist and Fellow of the Institute of Physics (U.K.), a Life and Honorary Fellow of the Institute of Physics, Malaysia, and a Life Fellow of the Singapore Institute of Physics and the Samahang Pisika ng Pilipinas. 